\title{
CRESCIMENTO DE PANICUM MAXIMUM CV. BRS ZURI EM RESPOSTA A RIZOBACTÉRIA E NITROGÊNIO
}

Angelita Aparecida Coutinho Picazevicz' ${ }^{1}$, Leonardo dos Santos França Shocknesss ${ }^{1}$, Arnaldo Libório Santos Filho², Izabel Rodrigues do Nascimento ${ }^{3}$, Lariana Diniz $\mathrm{Maciel}^{3}$, Lucas Rodrigues da Silva ${ }^{3}$, Gabriel Elias Gil Costa ${ }^{4}$

\begin{abstract}
RESUMO - Avaliou-se o crescimento de Panicum maximum cv. BRS Zuri em resposta a Azospirillum brasilense e adubação com nitrogênio. $\mathrm{O}$ experimento foi realizado em casa de vegetação, no delineamento inteiramente casualizado em esquema fatorial 2 × 2, com 8 repetições, considerando a ausência e a presença de Azospirillum brasilense inoculado nas sementes e nitrogênio $\left(50 \mathrm{~kg} \mathrm{ha}^{-1}\right)$ aplicado no solo. Verificou-se interação dupla entre os fatores, sendo que na ausência da adubação nitrogenada, por ocasião da semeadura, Azospirillum brasilense foi eficiente no aumento da altura das plantas. Além disso, a inoculação das sementes com este microrganismo resultou no aumento da massa seca da parte aérea, nitrogênio, potássio, cálcio e magnésio total acumulado na parte aérea de Panicum maximum cv. BRS Zuri.
\end{abstract}

Palavras chave: bactéria diazotrófica, espécie forrageira, fertilizante químico, RPCPs.

\section{PANICUM MAXIMUM CV. BRS ZURI GROWTH IN RESPONSE TO RHIZOBACTERIA AND NITROGEN}

\begin{abstract}
The growth of Panicum maximum cv. BRS Zuri in response to Azospirillum brasilense and nitrogen. The experiment was carried out in a greenhouse, in a completely randomized design in a $2 x$ 2 factorial scheme, with 8 replications, considering the absence and presence of Azospirillum brasilense inoculated in the seeds and nitrogen (50 $\left.\mathrm{kg} \cdot \mathrm{ha}^{-1}\right)$ applied to the soil. There was a double interaction between the factors, and in the absence of nitrogen fertilization at the time of sowing, Azospirillum brasilense was efficient in increasing plant height. In addition, seed inoculation with this microorganism resulted in increased shoot dry mass, nitrogen, potassium, calcium and total magnesium accumulated in the shoot Panicum maximum cv. BRS Zuri.
\end{abstract}

Keywords: chemical fertilizer, diazotrophic bacteria, fodder species, PGPR.

\section{INTRODUÇÃO}

A criação extensiva é uma das técnicas da atividade pecuária predominante no Brasil. Sendo que, as pastagens cultivadas é a principal fonte de alimentação do rebanho (Costa et al., 2004; Brasil, 2018). Diante disso, é essencial o manejo adequado da planta forrageira, visando reduzir a escassez de alimento para os animais e, também a degradação do solo, bem como da pastagem. Entre as técnicas de manejo, que se destacam, há as adubações que possuem a finalidade de atender a demanda nutricional da planta (Costa et al., 2010; Silva et al., 2013; Galindo et al., 2018).

Os adubos nitrogenados são essenciais no cultivo de espécies forrageiras. Contudo, o uso de quantidades excessivas e/ou carência destes insumos, dependendo da fonte, ocasiona degradação do solo, como por exemplo, a acidificação do meio e, também, lixiviação de bases (Rosado et al., 2014). Como alternativa a esta situação, plantas forrageiras da família Poaceae, podem ser beneficiadas pela ação de microrganismos considerados benéficos para os vegetais, como as rizobactérias

${ }^{1}$ Professor (a) de Agronomia do Instituto Federal de Rondônia/Campus Cacoal

${ }^{2}$ Engenheiro Agrônomo do Instituto Federal de Rondônia/Campus Cacoal

${ }^{3}$ Alunos do Curso de Zootecnia do Instituto Federal de Rondônia/Campus Cacoal

${ }^{4}$ Aluno do Curso Técnico em Agropecuária do Instituto Federal de Rondônia/Campus Cacoal. E-mail: angelita.aparecida@ifro.edu.br 
promotoras do crescimento de plantas (RPCPs), entre estas, Azospirillum brasilense (Oliveira et al., 2007; Vogel et al., 2014; Andrade et al., 2019).

As RPCPs, além da fixação biológica de nitrogênio, apresentam mecanismo de produção de compostos que promovem o crescimento dos vegetais, como fitormônios, solubilização de fósforo e potássio, produção de sideróforos e enzimas de hidrólise (Araújo et al., 2012; Tan et al., 2014). Em espécies vegetais utilizadas em pastagens, tais como, Panicum maximum Jacq. cv. Áries e Brachiaria brizantha cv. Marandu, estirpes de Azospirillum brasilense contribuíram para o aumento em crescimento e biomassa total das plantas (Guimarães et al., 2011; Spode et al., 2016).

A utilização de RPCPs pode contribuir para redução de gastos com insumos e minimização de impactos ambientais, além de, propiciar o crescimento da planta (Moreira et al., 2013). Neste sentido, o objetivo deste trabalho foi avaliar os efeitos isolados e combinados de Azospirillum brasilense e nitrogênio no crescimento de Panicum maximum cv. BRS Zuri.

\section{MATERIAL E MÉTODOS}

O experimento com Panicum maximum cv. BRS Zuri foi conduzido em casa de vegetação, seguindo o delineamento inteiramente casualizado em arranjo fatorial $2 \times 2$, cujos fatores corresponderam à ausência e presença de Azospirillum brasilense inoculado nas sementes e nitrogênio aplicado no solo. Considerou-se para cada um dos tratamentos 8 repetições, totalizando 32 unidades experimentais, as quais constituíram-se de vasos de policloreto de polivinila (PVC) com diâmetro de $200 \mathrm{~mm}$, altura de $50 \mathrm{~cm}$ e volume de $15,7 \mathrm{dm}^{3}$.

O solo utilizado como substrato foi retirado da camada superficial $(0-20 \mathrm{~cm})$ de uma área em pousio e antes de ser adicionado aos vasos elevou-se seu nível de fertilidade mediante adubação fosfatada com $100 \mathrm{mg}$ de $\mathrm{P}$ na forma de superfosfato simples $\left(18 \%\right.$ de $\left.\mathrm{P}_{2} \mathrm{O}_{5}\right)$ e potássica com $100 \mathrm{mg}$ de $\mathrm{K}$ na forma de cloreto de potássio (58\% de $\mathrm{K}_{2} \mathrm{O}$ ) quinze dias antes da semeadura. Na instalação do experimento as características químicas e físicas do solo, determinadas de acordo com Embrapa (1997), foram: $\mathrm{pH}$ $\left(\mathrm{CaCl}_{3}\right)=5,7$; matéria orgânica $=33,9 \mathrm{~g} \cdot \mathrm{dm}^{-3} ; \mathrm{P}=6,0 \mathrm{mg} \cdot \mathrm{dm}^{-3}$; $\mathrm{K}=86,9 \mathrm{mg} \cdot \mathrm{dm}^{-3} ; \mathrm{Ca}=3,85 \mathrm{cmol}_{\mathrm{c}} \cdot \mathrm{dm}^{-3} ; \mathrm{Mg}=1,36 \mathrm{cmol}_{\text {c }}$. $\mathrm{dm}^{-3} ; \mathrm{Al}=0,0 \mathrm{cmol}_{\mathrm{c}} \cdot \mathrm{dm}^{-3} ; \mathrm{H}+\mathrm{Al}=3,08 \mathrm{cmol}_{\mathrm{c}} \cdot \mathrm{dm}^{-3}$; soma de bases $=5,44 \mathrm{cmol} \cdot \mathrm{dm}^{-3} ; \mathrm{CTC}=8,52 \mathrm{cmol}_{\mathrm{c}} \mathrm{dm}^{-3}$; saturação por bases $=63,85 \%$; areia $=656$ g. $\mathrm{kg}^{-1}$; silte $=073 \mathrm{~g} . \mathrm{kg}^{-1}$; argila $=271 \mathrm{~g} \cdot \mathrm{kg}^{-1}$.
A fonte da rizobactéria utilizada foi inoculante comercial líquido à base de Azospirillum brasilense estirpes AbV5 e AbV6, contendo 2,0 x $10^{8}$ unidades formadoras de colônias (UFC) $\mathrm{mL}^{-1}$. Procedeu-se a aplicação do inoculante nas sementes em dose de $20 \mathrm{~mL} \cdot \mathrm{kg}^{-1}$. Após a secagem das sementes à sombra estas foram semeadas em profundidade padrão de $0,5 \mathrm{~cm}$. $\mathrm{O}$ nitrogênio na forma de ureia foi adicionado ao solo em quantidade equivalente a 50 kg.ha ${ }^{-1}$ e incorporado manualmente a $2 \mathrm{~cm}$ de profundidade no momento da semeadura. Aos dez dias após a emergência das plântulas de $P$. maximum foi realizado o desbaste, mantendo-se apenas a planta considerada mais vigorosa por vaso.

No período experimental as irrigações foram realizadas de forma manual e regular, visando manter a umidade do solo. Além de monitoradas, no interior da casa de vegetação, a temperatura e a umidade relativa do ar, por meio de data logger. A temperatura do solo foi verificada diariamente utilizando-se termômetro tipo espeto, a $14 \mathrm{~cm}$ de profundidade. As médias de temperatura e umidade do ar obtidas corresponderam a $27^{\circ} \mathrm{C}$ e $80 \%$. A temperatura média do solo no decorrer do período experimental foi de $25^{\circ} \mathrm{C}$.

$\mathrm{O}$ experimento foi avaliado quando no mínimo $50 \%$ das plantas atingiram $75 \mathrm{~cm}$ de altura. A altura das plantas foi obtida por medição da base ao extremo da folha de maior extensão, e o número de perfilho por contagem individualizadas.

Em seguida, as plantas foram cortadas rente ao solo para obtenção da massa seca da parte aérea. Posteriormente, foi realizada a limpeza das raízes mediante lavagem destas sobre peneiras. Para a obtenção das massas secas de parte aérea e de raiz, estas foram submetidas a secagem em estufa a $65^{\circ} \mathrm{C}$ e pesagem até verificação de valores constantes de suas massas secas. A massa total seca foi obtida pelo somatório das massas de raiz e parte aérea secas. A partir do material da parte aérea seco, após este ser triturado, foi determinado o nitrogênio, fósforo, potássio, cálcio, magnésio e enxofre acumulado na parte aérea (Embrapa, 2009).

A análise estatística consistiu em verificar inicialmente a presença de dados discrepantes (Grubbs, 1969), a normalidade dos erros (Shapiro \& Wilk, 1965) e a homogeneidade das variâncias (Bartlett, 1937). Os dados da massa seca da parte aérea e cálcio total acumulado na parte aérea das plantas não atenderam a normalidade dos erros, sendo transformados para $\log \mathrm{X}$ e $\sqrt{\mathrm{X}}$, respectivamente. Por outro lado, os dados da altura das plantas não atenderam a homogeneidade das variâncias, sendo transformados em $\mathrm{X}^{2}$. $\mathrm{O}$ teste $\mathrm{F}$ foi aplicado para 
verificar os efeitos isolados (independentes) e/ou combinados (interação) do Azospirillum brasilense e nitrogênio nas plantas. Para as interações significativas $(\mathrm{p}<0,05)$, efetuouse o desdobramento da análise de variância para avaliar os efeitos de um fator dentro do outro. As análises foram realizadas com auxílio do programa estatístico Sisvar (Ferreira, 2011).

\section{RESULTADOS E DISCUSSÃO}

Houve efeito isolado de $A$. brasilense na massa seca da parte aérea, nitrogênio, potássio, cálcio e magnésio total acumulado na parte aérea das plantas de $P$. maximum cv. BRS Zuri (Tabela 1). Estes resultados sugerem a ação deste microrganismo diazotrófico como rizobactéria promotora do crescimento de plantas (RPCPs), concordando com Melo (1998) que inclui neste grupo, entre outros exemplos, Azospirillum brasilense.

Tabela 1 - Efeito de Azospirillum brasilense na massa seca da parte aérea (MSPA), nitrogênio (NAPA), potássio (KAPA), cálcio (CaAPA) e magnésio (MgAPA) total acumulado na parte aérea de plantas de Panicum maximum cv. BRS Zuri

\begin{tabular}{lccr}
\hline \multirow{2}{*}{ Variáveis } & \multicolumn{2}{c}{ Azospirillum } & \multicolumn{2}{c}{ CV } \\
\cline { 2 - 3 } & Ausêncilense & Presença & $(\%)$ \\
\hline MSPA $(\mathrm{g})^{1}$ & $30,66 \mathrm{~b}$ & $35,88 \mathrm{a}$ & 4,61 \\
NAPA (mg) & $352,79 \mathrm{~b}$ & $490,02 \mathrm{a}$ & 21,53 \\
KAPA (mg) & $698,10 \mathrm{~b}$ & $851,79 \mathrm{a}$ & 20,06 \\
CaAPA (mg) & $115,71 \mathrm{~b}$ & $144,29 \mathrm{a}$ & 10,57 \\
MgAPA (mg) & $75,78 \mathrm{~b}$ & $100,17 \mathrm{a}$ & 22,60 \\
\hline
\end{tabular}

Médias seguidas de letras distintas na linha diferem $(\mathrm{p}<0,05)$ entre si pelo teste $\mathrm{F}$.

${ }^{1}$ Resultados originais cujos dados foram transformados em log X para a análise, uma vez que, não tendiam a normalidade dos erros.

${ }^{2}$ Resultados originais cujos dados foram transformados em $\sqrt{\mathrm{x}}$ para a análise, uma vez que, não atendiam a normalidade dos erros.

A massa seca da parte aérea teve aumento de aproximadamente $15 \%$, evidenciando o efeito benéfico desta bactéria diazotrófica para o crescimento das plantas, representando aumento da biomassa da parte aérea. Esta situação pode estar relacionada, principalmente, a fixação biológica de nitrogênio, a incrementos de nutrientes acumulados na planta, além da produção de metabólitos que são produzidos pelas RPCPs, como por exemplo, fitormônios (Steenhoudt \& Vanderleyden, 2000). Aumento da massa seca da parte aérea em espécies forrageiras inoculadas com bactérias do gênero Azospirillum foram observados em trabalhos realizados por Brasil et al. (2005) e Guimarães et al. (2011).

A inoculação de $A$. brasilense nas sementes aumentou o acúmulo total na parte aérea das plantas do nitrogênio em $28 \%$, potássio $18 \%$, cálcio $20 \%$ e magnésio $24 \%$. O acúmulo do nitrogênio deve-se a contribuição deste microrganismo na fixação biológica de nitrogênio, propiciando a disponibilidade desse elemento para a planta. Além disso, o acréscimo de nutrientes como potássio, cálcio e magnésio acumulados na parte aérea das plantas pode ter ocorrido em razão do possível aumento de pelos radiculares e superfície de contato das raízes o que potencializou maior absorção e acúmulo destes macronutrientes. Em espécie de poácea, como o milho, Rosa (2017) verificou que plantas que foram inoculadas com Azospirillum brasilense extraíram maiores quantidades de macronutrientes, com exceção de cálcio e enxofre.

A inoculação de Azospirillum brasilense nas sementes na ausência de nitrogênio aplicado no solo resultou no aumento da altura das plantas (Tabela 2). Por outro lado, A. brasilense inoculado nas sementes não teve efeito quando se efetuou a adubação nitrogenada para esta variável. Neste sentido, verifica-se que o uso das estirpes de A. brasilense AbV5 e AbV6 não potencializou o efeito da adubação nitrogenada. Entretanto, ressalta-se a importância da inoculação das sementes com esta bactéria diazotrófica na ausência da utilização de adubos nitrogenados na semeadura, uma vez que, a altura de plantas teve acréscimo em $15 \%$ quando as sementes de $P$. maximum cv. BRS Zuri foram inoculadas.

Tabela 2 - Altura de plantas de Panicum maximum cv. BRS Zuri em função da interação entre Azospirillum brasilense e nitrogênio

\begin{tabular}{lcccc}
\hline \multirow{2}{*}{ Variável } & Azospirillum & \multicolumn{2}{c}{ Nitrogênio } & \multirow{2}{*}{ CV } \\
\cline { 3 - 4 } & brasilense & Ausência & Presença & $(\%)$ \\
\hline Altura & Ausência & $36,13 \mathrm{Bb}$ & $43,00 \mathrm{Aa}$ & \\
$(\mathrm{cm})^{1}$ & Presença & $42,56 \mathrm{Aa}$ & $43,88 \mathrm{Aa}$ & 16,74 \\
\hline
\end{tabular}

Médias seguidas de mesma letra, maiúsculas na coluna e minúscula na linha, não diferem $(p>0,05)$ entre si pelo teste $F$.

${ }^{1}$ Resultados originais cujos dados foram transformados em $\mathrm{X}^{2}$ para a análise de variância por não atenderem a homogeneidade de variância.

O incremento na altura das plantas quando se efetuou a inoculação das sementes com A. brasilense, 
deve-se ao fato deste microrganismo ser diazotrófico, portanto, contribui via fixação biológica de nitrogênio, na disponibilização deste macronutriente, propiciando o crescimento vegetativo das plantas (Hungria, 2011). Andrade et al. (2019) verificaram que $A$. brasilense contribuiu efetivamente no aumento em produtividade de P. maximum cv. BRS Tamani.

Não houve efeito $(\mathrm{p}>0,05)$ da inoculação das sementes com Azospirillum brasilense tampouco da adubação nitrogenada para o número de perfilhos, massas secas da raiz e total, fósforo e enxofre total acumulado na parte aérea das plantas. O teor de fósforo no solo na ocasião de instalação do experimento pode ser categorizado como baixo, o que contribuiu, possivelmente, para não ter ocorrido efeito dos fatores. Relacionado a massa seca de raiz Oliveira et al. (2007) não verificaram incrementos desta variável em Brachiaria brizantha cv. Marandu em reposta a inoculação com Azospirillum brasilense. Por outro lado, Fernandes (2016) constatou acréscimo no número de perfilhos de Brachiaria decumbens quando as sementes foram inoculadas com este microrganismo.

\section{CONCLUSÕES}

Azospirillum brasilense, na ausência da adubação nitrogenada aumenta a altura de Panicum maximum cv. BRS Zuri.

Azospirillum brasilense incrementa a massa seca da parte aérea, nitrogênio, potássio, cálcio e magnésio total acumulado na parte aérea de Panicum maximum cv. BRS Zuri.

Azospirillum brasilense e/ou a adubação nitrogenada não incrementa as massas secas da raiz e total, fósforo e enxofre total acumulado na parte aérea de Panicum maximum cv. BRS Zuri.

\section{LITERATURA CITADA}

ANDRADE, R.A.; PORTO, M.O.; CAVALI, J.; FERREIRA, E.; BERGAMIN, A.C.; SOUZA, F.R.; AGUIAR, I.S. Azospirillum brasilense e fosfato natural reativo no estabelecimento de forrageira tropical. Revista de Ciências Agrária, v.42, n.1, p.146 154, 2019. DOI: http://dx.doi.org/10.19084/RCA18282.

ARAÚJO, F.F.; GUABERTO, L.M.; SILVA, I.F. Bioprospecção de rizobactérias promotoras de crescimento em Brachiaria brizantha. Revista Brasileira de Zootecnia, Viçosa, MG, v.41, n.3, p.52-527, 2012. DOI: http://dx.doi. org/10.1590/S151635982012000300007.
BARTLETT, M.S. Properties of sufficiency and statistical tests. Proceedings of the Royal Society of London, v.160, n.901, p.268-282, 1937. DOI: https://doi.org/10.1098/ rspa.1937.0109.

BRASIL. Pecuária de baixa emissão de carbono: tecnologias de produção mais limpa e aproveitamento econômico dos resíduos da produção de bovinos de corte e leite em sistemas confinados. Brasília, DF: Ministério da Agricultura, Pecuária e Abastecimento, 2018. 88 p.

BRASIL, M.S.; BALDANI, V.L.D.; BALDANI, J.I.; SOUTO, S.M. Efeitos da inoculação de bactérias diazotróficas em gramíneas forrageiras do Pantanal. Pasturas Tropicales, v.27, n.3, p.22-33, 2005.

COSTA, K.A.P.; FAQUIN, V.; OLIVEIRA, I.P. Doses e fontes de nitrogênio na recuperação de pastagens do capim-marandu. Revista Arquivo Brasileiro de Meidcina Veterinária e Zootecnia, v.62, n.1, p.192-199, 2010). DOI: http://dx.doi.org/10.1590/S0102-09352010000100026.

COSTA, N.L. Formação, manejo e recuperação de pastagens em Rondônia. Porto Velho: EMBRAPA, 2004. 219p.

EMBRAPA. Manual de métodos de análise de solo. 2. ed. Rio de Janeiro: EMBRAPA, 1997. 212p.

EMBRAPA. Manual de análises químicas de solos, plantas e fertilizantes. 2. ed. Brasília, DF: EMBRAPA, 2009. 627p.

FERNANDES, J.S. Azospirillum brasilense e adubação nitrogenada na Brachiaria decumbens. Dissertação (Mestrado em Agronomia). Dourados, MS: UFGD, 2016. 49p.

FERREIRA, D.F. Sisvar: A computer statistical analysis system. Ciência e Agrotecnologia, v.35, p.1039-1042, 2011.

GALINDO, F.S.; BUZETTI, S.; TEIXEIRA FLHO, M.C.M.; DUPAS, E.; CARVALHO, F.C. Manejo da adubação nitrogenada no capim-mombaça em função de fontes e doses de nitrogênio. Revista de Ciências Agrária, v.41, n.4, p.900-913, 2018. DOI: http://dx.doi. org/10.19084/RCA18131.

GRUBBS, F.E. Procedures for detecting outlying observations in samples. Technometrics, v.11, n.1, p.1-21, 1969. DOI: https://doi.org/10.1080/00401706.1969.10490657.

GUIMARÃES, S.L.; BONFIM-SILVA, E.M.; KROTH, B.E.; MOREIRA, J.C.F.; REZENDE, D. Crescimento e desenvolvimento inicial de Brachiaria decumbens inoculada com Azospirillum spp. Enciclopédia Biosfera, v.7, n.13, p.286-295, 2011. 
HUNGRIA, M. Inoculação com Azospirillum brasilense: inovação em rendimento a baixo custo. Londrina: Embrapa Soja, 2011. 38p. (Documentos, 325).

MELO, I.S. Rizobactérias promotoras de crescimento de plantas: descrição e potencial de uso na agricultura. In: MELO, I. S. de; AZEVEDO, J. L. de. (Ed.). Ecologia microbiana. Jaguariúna: Embrapa CNPMA, 1998. p. 87116.

MOREIRA, F.M.S.; LIMA, A.S.; JESUS, E.C.; SILVA, K.; NÓBREGA, R.S.A.; FLORENTINO, L.A. Bactérias fixadoras de nitrogênio atmosférico que nodulam leguminosas. In: MOREIRA, F.M.S.; CARES, J.E.; ZANETTI, R.; STÜRMER, S.L. (Ed.). O ecossistema solo: componentes, relações ecológicas e efeitos na produção vegetal. Lavras: Ed. da UFLA, 2013. p.325-340.

OLIVEIRA, P.P.A.; OLIVEIRA, W.S.; BARIONI JÚNIOR, W. Produção de forragem e qualidade de Brachiaria brizantha $c v$. Marandu com Azospirillum brasilense $e$ fertilizada com nitrogênio. São Carlos: Embrapa Pecuária Sudeste, 2007. 6p. (Circular técnica, 54).

ROSA, P.A.L. Acúmulo de matéria seca, extração e exportação de nutrientes por híbridos de milho inoculados com Azospirillum brasilense. Dissertação (Mestrado em Agronomia) Ilha Solteira, SP: UNESP, 2017. 98p.

ROSADO, T.L.; GONTIJO, I.; ALMEIDA, M.S.; ANDRADE, F.V. Fontes e doses de nitrogênio e alterações nos atributos químicos de um latossolo cultivado com capim-mombaça. Revista Brasileira de Ciência do Solo, v.28, n.3, p.840-849, 2014. DOI: http://dx.doi.org/10.1590/ S0100-06832014000300015.
SHAPIRO, S.S.; WILK, M. B. An analysis of variance test for normality (complete samples). Biometrika, v.52, n.3/4, p.591-611, 1965. DOI: https://doi.org/10.2307/2333709.

SILVA, D.R.G.; COSTA, K.A.P.; FAQUIN, V.; OLIVEIRA, I.P.; BERNARDES, T.F. Doses e fontes de nitrogênio na recuperação das características estruturais e produtivas do capim-marandu. Revista Ciência Agronômica, v.44, n.1, p.184-191, 2013.

SPODE, M.R.; ZUFFO, D.H.; RENNER, S.; GRUNUTZKY, J.P.; SALVATTI, E.R.; LAJÚS, C.R. Avaliação de diferentes tecnologias para tratamento de semente no crescimento inicial de Panicum maximum Jacq. cv. Àries. Unoesc \& Ciência, v.7, n.2, p.155-160, 2016.

STEENHOUDT, O.; VANDERLEYDEN, J. Azospirillum, a free-living nitrogen-fixing bacterium closely associated with grasses: genetic, biochemical and ecological aspects. Microbiology Reviews, v.24, n.4, p.487-506, 2000. DOI: https://doi.org/10.1111/j.1574-6976.2000.tb00552.x.

TAN, K.Z.; RADZIAH, O.; HALIMI, M.S.; KHAIRUDDIN, A.R.; HABIB, S.H.; SHAMSUDDIN, Z.H. Isolation and characterization of rhizobia and plant growth-promoting rhizobacteria and their effects on growth of rice seedlings. American Journal of Agricultural and Biological Science, v.9, n.3, p.342-360, 2014. DOI: https:// doi.org/10.3844/ajabssp.2014.342.360.

VOGEL, G.F.; MARTINKOSKI, L.; RUZICKI, M. Efeitos da utilização de Azospirillum brasilense em poáceas forrageiras: importâncias e resultados. Revista Agropecuária Científica no Semiárido, v.10, n.1, p.01-06, 2014.

Recebido para publicação em 02/09/2019 e aprovado em 06/02/2020. 